\title{
Serological surveillance of avian influenza virus in nepal
}

\begin{abstract}
A serological survey for Avian Influenza Virus (AIV) subtype H5, H7 and H9 antibodies in domestic ducks was carried out in 2009 at Central Veterinary Laboratory (CVL), Kathmandu, Nepal. A total of 1000 serum samples were tested from various localities of 11 districts of Nepal, categorized as to be at high risk for the introduction of Highly Pathogenic Avian Influenza Virus (HPAIV) of H5N1 subtype. Sero-positive result against AIV H5 was found in three districts of eastern region with the highest prevalence $(6.28$ $\%)$ in Jhapa $(\mathrm{p}<0.001)$. Likewise, sero-positive samples against AIV H9 were detected in Chitwan, Kapilbastu, Nawalparasi and Kaski districts. However, none of the samples was found to be sero-positive against AIV H7. All the samples positive against $\mathrm{H} 5$ were sampled in December 2008 exclusively $(p<0.001)$. In contrast, two samples collected before September 2008 and three samples after this time until January 2009 were sero-positive against AIV H9. Our findings indicate higher prevalence of AIV subtype H5 compared to $\mathrm{H} 7$ and $\mathrm{H} 9$ in duck species of Nepal.
\end{abstract}

Keywords: Avian influenza virus, Ducks, Nepal, CVL, Surveillance

\author{
Volume 4 Issue I - 2016 \\ Shanti Pandey, ${ }^{1,2}$ Shardulendra Prasad \\ Sherchand, ${ }^{1,3}$ Poornima Manandhar, ${ }^{4}$ Nabaraj \\ Pokhrel,' Anja Globig, ${ }^{5}$ Samendra Sherchan ${ }^{6}$ \\ 'National College, Khusibu, Kathmandu, Nepal \\ ${ }^{2}$ The University of Southern Mississippi, Hattiesburg, Mississippi, \\ USA \\ ${ }^{3}$ Department of Microbiology, Immunology and Parasitology, \\ Louisiana State University Health Sciences Center, \\ USA \\ ${ }^{4}$ Central Veterinary Laboratory, Kathmandu, Nepal \\ ${ }^{5}$ Fiedrich-Loeffler-Institut, Insel Riems, Germany \\ ${ }^{6}$ Department of Global Environmental Health Sciences, Tulane \\ University, USA
}

\section{Correspondence: Samendra Sherchan, Assistant Professor, Department of Global Environmental Health Sciences, Tulane University, New Orleans, LA, 70I I 2, USA, Tel 5049887283; Email sshercha@tulane.edu \\ Received:September 19, 2016 | Published: November 02, 2016}

Abbreviations:AIV, Avian Influenza Virus; CVL, Central Veterinary Laboratory; HPAIV, Highly Pathogenic Avian Influenza Virus; AI, Avian Influenza; LPAIV, Low Pathogenic Avian Influenza Viruses

\section{Introduction}

Avian Influenza (AI) is an infectious disease of birds caused by type A strains of the Influenza Virus. While all birds are thought to be susceptible to infection with AI viruses, many wild bird species particularly birds of the orders Anseriformes (ducks, geese and swans) and Charadriiformes (gulls, waders and terns) are known as reservoirs (CDC). The domestic ducks in South East Asia is the principal host of Influenza A viruses where free-grazing duck feed year round in rice paddies appear to be a critical factor in HPAI persistence and spread and also has a central role in the generation and maintenance of the H5N1 virus. ${ }^{1-3}$

It is not clear how AI viruses are maintained from year to year, but there is evidence that the viruses in duck populations survive in their habitat. Ducks have been shown to excrete virus for as long as 30 days, so it would not require many virus passages to maintain the viruses in the population. ${ }^{4}$ It is possible that the viruses are maintained even at low level in the wild duck by transmission to susceptible birds until the next breeding season resulting in a new group of susceptible juveniles. $^{5}$

While the low pathogenic avian influenza viruses (LPAIV) do not have any impact on wild bird population, highly pathogenic avian influenza viruses (HPAIV) can also seriously harm them. Often, wild birds found dead in the vicinity of HPAI outbreaks in poultry, were infected with the same virus. With the onset of HPAIV H5N1 circulation in Asia and its spread to Europe and Africa major concern was that the HPAIV H5N1 could also become part of the AIV-reservoir maintained asymptomatically by wild birds. However, intense surveillance studies in wild birds in Europe ruled out endemicity of HPAIV H5N1 within wild bird populations. ${ }^{6}$

More recently, some HPAI viruses (e.g., H5N1) have been found to cause no illness in some poultry, such as ducks. LPAI viruses have the potential to evolve into HPAI viruses and this has been documented in some poultry outbreaks. Avian influenza A viruses of the subtypes $\mathrm{H} 5$ and $\mathrm{H} 7$, including $\mathrm{H} 5 \mathrm{~N} 1, \mathrm{H} 7 \mathrm{~N} 7$, and $\mathrm{H} 7 \mathrm{~N} 3$ viruses, have been associated with HPAI, and human infection with these viruses have ranged from mild (H7N3, H7N7) to severe and fatal disease (H7N7, H5N1). In general, direct human infection with avian influenza viruses occurs very infrequently, and has been associated with direct contact (e.g., touching) infected sick or dead infected birds. ${ }^{7}$

The domestic duck in Southeast Asia is the principal host of Influenza $\mathrm{A}$ viruses and also has a central role in the generation and maintenance of the H5N1 virus. ${ }^{1,3}$ Several duck species are naturally resistant to $\mathrm{HP}$ Asian $\mathrm{H} 5 \mathrm{~N} 1$ influenza viruses and can transmit the virus to domestic animals including humans. These duck species can shed and spread virus from both the respiratory and intestinal tracts showing few or no disease signs, the absence of disease signs in some duck species has led concept that ducks are the "Trojan horses" of H5N1 in their surreptitious spread of virus. Clearly, ducks play a complex and vital role in the biology and the overall natural history of influenza including H5N1 HPAI viruses. ${ }^{8}$ Following this study, Nepal has suffered perennial $\mathrm{H} 5 \mathrm{~N} 1$ outbreaks in poultry, over 234 outbreaks have occurred since 2009. ${ }^{3,9}$ The main objective of this study was to assess the presence of Avian Influenza Virus (AIV) subtype H5, H7 and $\mathrm{H} 9$ antibodies in domestic ducks in Nepal prior to this outbreak. 


\section{Methodology}

\section{Sample and study area}

Approximately 1000ul of each duck serum samples were received from eleven districts out of 75 districts in Nepal: Jhapa, Morang, Sunsari, Rautahat, Chitwan, Nawalparasi, Kapilbastu, Kaski, Banke, Bardiya and Kanchanpur.

\section{Blood sample collection}

A total of 1000 blood samples were collected in varied time course, allowed to clot and sera were separated and preserved at $-20^{\circ}$ $\mathrm{C}$ at Central Veterinary Laboratory (CVL), Kathmandu. Out of all, 389 (38.9\%) had been preserved from Pant and Selleck ${ }^{5}$ at $-20^{\circ} \mathrm{C}$ while the remaining 611(61.1\%) were collected contemporarily with the study period (September 2008-May 2009). All the samples were from High Risk District (HRD) regions.

\section{Haemagglutination (HA) and Haemagglutination inhibition (HI) tests}

The serum samples were tested to determine the antibodies against AIV- subtypes H5, H7 and H9. The antigens used were received from Weybridge, UK.

\section{Test Procedure}

In order to monitor the antibody titer in duck serum samples, the protocol for HA/ HI tests was followed according to the OIE Manual. And the ELISA tests were performed as instructed in the FLUDETECTTM Blocking ELISA procedure.

\section{Result Interpretation}

Positive HI test: Appearance of distinct button or tear- shaped.

Negative HI test: Appearance of agglutination of RBCs (no distinct button).

\section{Statistical analysis}

The statistical of the data was performed by SPSS (version 11.5). The Chi-square test was calculated to observe any significant relationships among the variables and $\mathrm{p}$-value $<0.001$ was considered statistically significant in the test.

\section{Results}

Among 1000 serum samples derived from ducks, 26 (2.6\%) samples were found to contain AIV type A antibodies (Tested for H5, H7 and H9 subtypes only) by HI test. Among positive for AIV type A antibodies, only $21(2.1 \%)$ samples specifically contained H5 antibodies while $5(0.5 \%)$ samples were positive against H9 subtype. However, none of the sample showed sero-positive result for antibodies against $\mathrm{H} 7$ subtype (Table 1).

Table I Detection of different subtypes of AIV type A antibodies by HI test

\begin{tabular}{lll}
\hline Sub Type & Number of samples tested & \% Positive \\
\hline H5 & 1000 & 2.1 \\
H9 & 1000 & 0.5 \\
H7 & 1000 & 0 \\
\hline
\end{tabular}

On doing further verification, samples having $\mathrm{H} 5$ and $\mathrm{H} 9$ hemagglutinin inhibiting antibodies in HI tests were found also to be positive as tested for AIV type A antibodies in ELISA test. Besides this, out of 55 samples from Jhapa district tested negative in HI test, 4 samples were found to be positive in ELISA test.

\section{District wise distribution of antibodies against AIV H5, $\mathrm{H} 9$ and $\mathrm{H7}$ subtypes}

Among 11 districts, samples containing the antibodies against H5 subtype were from eastern three districts. No sample from any district was found to be sero-positive against $\mathrm{H} 7$ subtype while samples containing $\mathrm{H} 9$ antibodies were derived from two districts each from central and western regions (Table 2).

Table 2 District wise distribution of AIV type A H5, $\mathrm{H} 7$ and $\mathrm{H} 9$ antibodies

\begin{tabular}{lllll}
\hline \multirow{2}{*}{ Districts } & \multicolumn{3}{l}{ No of Positive (\%) Against } & \multirow{2}{*}{ Total Sample Tested } \\
\cline { 2 - 4 } & H5 & H9 & H7 & \\
Jhapa & II (6.28) & 0 & 0 & 175 \\
Morang & $3(I .7 I)$ & 0 & 0 & 175 \\
Sunsari & $7(4.0)$ & 0 & 0 & 175 \\
Rautahat & 0 & 0 & 0 & 69 \\
Chitwan & 0 & $\mathrm{I}(\mathrm{I} .08)$ & 0 & 92 \\
Nawalparasi & 0 & $2(3.63)$ & 0 & 55 \\
Kapilbastu & 0 & $\mathrm{I}(\mathrm{I} .8 \mathrm{I})$ & 0 & 55 \\
Kaski & 0 & $\mathrm{I}(\mathrm{I} .8 \mathrm{I})$ & 0 & 55 \\
Banke & 0 & 0 & 0 & 26 \\
Bardiya & 0 & 0 & 0 & 47 \\
Kanchanpur & 0 & 0 & 0 & 76 \\
Total & $2 \mathrm{I}(2.1 \%)$ & $5(0.5 \%)$ & 0 & 1000 \\
\hline
\end{tabular}

$\mathrm{HI}$ Titers reading against $\mathrm{H5}$ and $\mathrm{H} 9$ subtype:

Among samples tested against H5 subtype, 21 (2.1\%) samples were found to be giving HI titer value $\geq 1: 32$. While, remaining 979 samples $(97.9 \%)$ showed $\mathrm{HI}$ titer value $\leq 1: 4$ giving non-specific results in HI tests (Table 3$)$. Likewise only 5 samples $(0.5 \%)$ showed the $\mathrm{HI}$ titer value $\geq 1: 32$. Rest of the samples showed $\mathrm{HI}$ titer value of $\leq 1: 4$ for $\mathrm{H} 9$ antibodies.

Table 3 Distribution of samples on the basis of $\mathrm{HI}$ titers against AIV-subtype H5

\begin{tabular}{lllllllllll}
\hline \multicolumn{1}{l}{$\begin{array}{l}\text { No of } \\
\text { S. No. samples (\%) }\end{array}$} & I:2 & I:4 I: I:8 & I:I6 & I:32 & I:64 & I:I 28 & I:256 \\
\cline { 2 - 10 } & $2 I(2 . I)$ & 0 & 0 & 0 & 0 & 13 & 8 & 0 & 0 \\
\hline & $979(97.9)$ & 919 & 60 & 0 & 0 & 0 & 0 & 0 & 0 \\
\hline
\end{tabular}

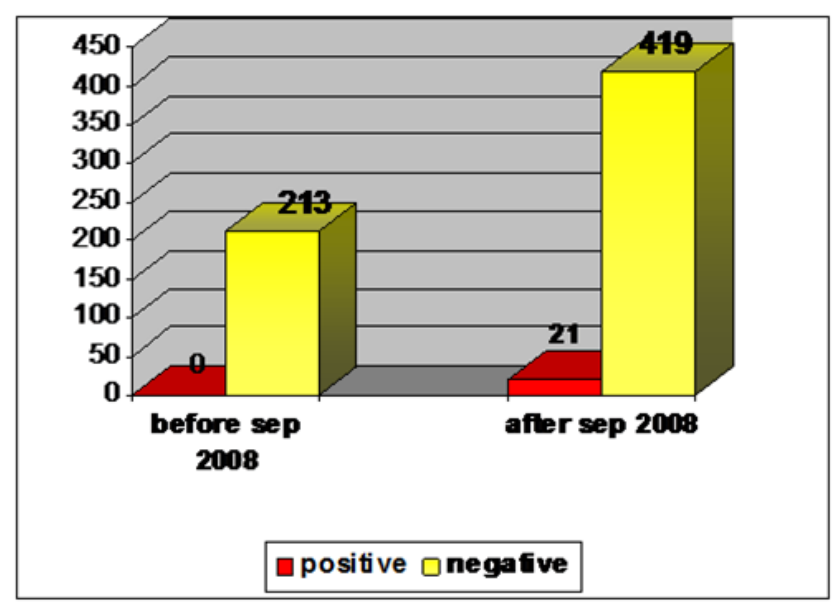

Figure I Time wise distribution of sero-prevalence status against H5.

\section{Sero-prevalence status against H5 subtype on the} basis of sampled time

Among 560 serum samples collected before September 2008, none of the sample was found to contain AIV subtype H5 antibodies. However, 21 (4.77\%) sera among 440 collected in December 2008 
exclusively contained AIV subtype H5 antibodies ( $<<0.001)$ (Figure 1). Likewise, only $2(0.35 \%)$ samples collected before Sep 2008 showed the sero-positive result of AIV subtype H9 antibody while 3 $(0.68 \%)$ samples out of 440 collected after September 2008 found to be sero-positive for these antibodies.

\section{Discussion}

AI outbreak was not reported till this research was started and suddenly it occurred in the beginning of 2009 in the Eastern Region of Nepal about $5 \mathrm{KM}$ away from the Nepal-India border thus adding our nation in the list of AI affected countries in the world. Though the nearby country India has already been reported the case, Nepal was remained untouched for long time because of strict quarantine check post, which might have prevented the entry of virus. However, there might be another route through which it might enter the country i.e. through the wild aquatic birds, which are natural reservoir of AIV. Furthermore, the open border with India is also another major concern from where the import of poultry products mostly occurs. ${ }^{10}$ Practice of illegal import of poultry and poultry product is also prevalent in the country and that might be another reason why Nepal acquired the devastating disease.

The total seropositive case was only $3 \%$ irrespective of the subtype of antibody. However, the study carried out by Al-Natour et al. ${ }^{11}$ reported $71 \%$ sero-prevalence among the poultry flocks. Likewise, Naeem et al. ${ }^{12}$ found $54.54 \%$ seropositive cases among poultry flocks. The higher sero-prevalence cases in these studies might be due to the higher number of poultries in the same flocks in relatively a smaller geographical area there. The lower sero-prevalence rate in this study is due to the inclusion of serum samples from wide range of geographical area where no cases of LPAI of HPAI outbreaks have been reported in Nepal. Furthermore, the samples were taken from the backyard ducks whose number in a flock was ranging from several to not more than ten.

Among the sero-positive cases, H5 antibody shares 21 (3.21\%, $\mathrm{n}=653)$ while $5(1.89 \%, \mathrm{n}=264)$ sero-positive cases were added by H9 antibody and no positive case $(\mathrm{n}=83$ ) was detected for $\mathrm{H} 7$ antibody. Numan and Siddique et al. ${ }^{13}$ carried out similar survey based in collection of serum samples for the determination of prevalence of avian influenza in flocks was in an area of Punjab using the Haemagglutination Inhibition (HI) test. The result showed that out of 14 sampled farms, three farms had antibodies against $\mathrm{H} 7$ subtype; two farms showed antibodies against both subtypes $\mathrm{H} 7$ and $\mathrm{H} 9$, while remaining 7 farms were negative for antibodies to AI.

Among all, 653 serum samples were tested for H5 antibody, 83 samples for $\mathrm{H} 7$ and 264 samples for $\mathrm{H} 9$ antibody. Out of 653 serum samples; 21 (3.21\%) samples found to be positive specifically for H5 antibody from HRD Jhapa, Morang and Sunsari. With the HI test, Only $11(9.3 \%, \mathrm{n}=107)$ from Jhapa and $3(2.4 \%, \mathrm{n}=124)$ from Morang were seropositive for $\mathrm{H} 5$ and Sunsari contributed for only $7(3.6 \%, n=186)$ seropositive results were found. In contrast, while using Blocking ELISA, 4 additional seropositive cases were detected in Jhapa district. This may be due to the more sensitivity of ELISA test than that of HI test. This is the first report of sero-prevalence of avian influenza type A subtype H5 in backyard ducks in Nepal. The highest prevalence rate in Jhapa indicates the circulation if the AI virus and continuous field challenge.

In spite of the presence of high levels if AI antibodies in the duck sera tested, no clinical cases were reported till early 2009 when HPAI $\mathrm{H} 5 \mathrm{~N} 1$ outbreak occurred in there. This showed the varied number of seropositive case in the studied localities with more seropositive in the region where risk of acquiring AI was higher. The seropositive ducks had no history of clinical signs. This finding is in correlation with the study carried out by, which also showed the higher seropositive cases in the farms near migratory routes of migratory waterfowl. Likewise, the positive flocks had 2-30 sero-positive cases out of 30 samples examined in each farm. In the present study, the serum sample were being collected just prior to the outbreak of AI in Jhapa in Nepal, the first ever case. This indicates that, ducks had been exposure to the HPAI earlier so that they developed antibodies against the H5 subtype. These districts are under the high-risk regions category because they lie near the Indian border plus illegal import of poultry and poultry products are also prevalent in these regions.

Among samples; tested for H5 antibody, 213 (32.2\%) samples were collected before the year 2008. Remaining 440 samples $(67.8 \%)$ were collected from mid 2008 to the beginning of 2009. None of the samples collected before the year 2008 showed sero-positivity for $\mathrm{H} 5$ antibody. While 21 samples $(4.77 \%, \mathrm{n}=440)$ were seropositive for H5 antibody, additional 4 sero-positive cases were determine by ELISA, which were collected between end of 2008 and beginning of 2009. The sero-positivity for H5 subtype in the ducks from HRD regions suggests that antibodies in the serum of ducks have been developed or produced due to exposure to the virus of subtype $\mathrm{H} 5$ irrespective of the NA subtype. Presence of AI virus type A antibodies indicates previous exposure to the virus. The contemporary outbreak of AI in poultry in the same region here also strongly supports the outcome without any doubt.

Samples tested for H5 antibody, 21 samples $(3.21 \%, \mathrm{n}=653)$ were found to be giving HI titer value $>1: 80$ while, 67 samples $(10.26 \%, \mathrm{n}$ $=653$ ) gave $\mathrm{HI}$ titer value $<1: 80$. As OIE recommends, sero-positivity is considered by the $\mathrm{HI}$ test showing $\mathrm{HI}$ titer $>1: 80$ where all of these samples had shown HI titer value more than 1: 320 . Thus these samples were confirmed as the seropositive for AI subtype H5. All these samples were verified by blocking ELISA test. All the samples giving $\mathrm{HI}$ titer value $>1: 80$ in $\mathrm{HI}$ test were found to be positive in the ELISA test too. Besides, 4 samples giving HI titer $<1: 80$ in HI tests were also gave positive result in the ELISA test. This depicts the sensitivity of ELISA is higher than that of HI test as found in the case of Adair et al. ${ }^{14}$ and Arenas et al. ${ }^{15}$ Contrary to this result, Zhou et al (1998) and Sala et al. ${ }^{16}$ reported higher sensitivity of HI test over the ELISA test. This variation may be due to the different diagnostic potential, principle and protocols provided for the tests.

The sero-positivity for H9 subtype is correlated with the findings by Shrestha. ${ }^{10}$ in which, 6 cases out of 1000 were positive for the presence of low pathogenic $\mathrm{H} 9$ subtype. The positive cases were found from the tracheal swab of poultry in Chitwan and Nuwakot districts. The sero-positivity for $\mathrm{H} 9$ subtype in this study was from Chitwan $(2.1 \%, n=48)$, Kapilbastu $(5 \%, n=20)$, Nawalparasi $(7.1 \%, n=28)$ and Kaski $(5 \%, \mathrm{n}=20)$. Pant. ${ }^{5}$ had reported the H9 seropositive cases from the poultry serum collected on October 2005 for the first time in Nepal. From this finding, it can be concluded that though few cases, low pathogenic H9 subtype is prevalent in Nepal and the study should be monitored strictly and carried out more intensively to establish the exact prevalence data to help minimize the risk of transmission and stop the spread of the virus. However, none of serum samples showed positive result for the $\mathrm{H} 7$ subtype. This result brings close similarity with the study carried out by Pant. ${ }^{5}$ who detected no AI subtype $\mathrm{H} 7$ in any serum sample tested with the ELISA followed by HI test.

The ducks from which serum samples were collected were apparently healthy without no signs and symptoms of AI. This bears the same result with the experiment carried out by $\mathrm{H}$ Kida et 
al. F(1980) experimentally inoculated Influenza viruses A/duck/ Hokkaido/5/77 (Hav7N2), A/budgerigar/Hokkaido/1/77 (Hav4Nav1), A/Kumamoto/22/76 (H3N2), A/Aichi/2/68 (H3N2), and A/New Jersey/8/76 (H1N1) into Peking ducks. The infected ducks shed the virus in the feces to high titers, but did not show clinical signs of disease and scarcely produced detectable serum antibodies. In this study NI test was not carried out because its procedure requires specialized expertise and reagents; consequently this testing is usually done in an OIE Reference Laboratory. However, it can be concluded that the ducks have exposure to the virus irrespective of the high or low pathogenic subtype $\mathrm{H} 5$ and $\mathrm{H} 9$ whilst no serum samples from all the regions tested for $\mathrm{H} 7$ subtype showed sero-positive result. Hence, from this study, $\mathrm{H}$ - subtype antibody present in the serum samples was detected as of $\mathrm{H} 5$ and $\mathrm{H} 9$ but NA subtype could not be determined. The high $\mathrm{HI}$ titer against $\mathrm{H} 5$ and $\mathrm{H} 9$ subtype and positive result in the blocking ELISA test is the indication for the presence of respective antibodies in the serum samples.

The sero-positivity in the sample was reported according to the HI titer shown by the antibodies present in the serum. As OIE recommends, HI titer value $>1: 80$ can be considered as the seropositivity. Hence, out of 653 serum samples tested for antibody against H5 subtype only 21 (3.21\%) samples shows HI titer up to $1: 1280$ and hence these samples are considered to be positive. While $67(10.26 \%)$ serum samples from HRD found to be non-specific as they showed HI titer value $1<1: 80$, that might be due to production of insignificant levels of antibodies or might be cross reactivity of some other antibodies or the less sensitivity of HI test. In addition, repeated thawing and freezing process might have also interfered the positive result by decreasing the efficacy of antibodies. Out of the 67 non-specific serum samples, 4 samples were shown to be positive by blocking ELISA. This is in accordance with the result of Adair et al. ${ }^{14}$ and Arenas et al.. ${ }^{15}$ who reported that the ELISA test is better than $\mathrm{HI}$ test.

FAO ${ }^{16}$ report suggest that high titer of virus occur in the late summer, when birds leave their northern breeding areas. The titers decrease as birds continue southwards. Nepal is situated in the southern part and migratory birds come to Nepal from the northern Siberian Province. Hence the titer might have become very less and thus were undetectable in this study. ${ }^{17}$ This finding also brings the opinion that exposure of ducks to low titer of AI infected bird might have resulted in the non-specific sero-positivity in the serum samples tested.

This outcome is in close relation to the study carried out by Hinshaw et al. ${ }^{18}$ found insignificant levels of antibodies while doing $\mathrm{HI}$ test in post infection sera from ducks. This suggested that avian influenza viruses might not induce a significant humoral response. Or the $\mathrm{HI}$ assay, the standard method for serologic detection of influenza Virus infection has been shown to be less sensitive for the detection of antibodies induced by avian influenza viruses. ${ }^{19}$ Thus, to get exact and accurate result, more sensitive ELISA test was run in addition to the $\mathrm{HA} / \mathrm{HI}$ test for the better result.

Thus this result indicates that the AI virus has been prevalent in avian species especially duck. The ducks are the natural reservoir of AI viruses. Study carried out by Hulse-Post et al. ${ }^{20}$ indicates that the ducks are true reservoir for the AI viruses. Wild waterfowl, including ducks, are the natural hosts of influenza A viruses. These viruses rarely caused disease in ducks until 2002. When some H5N1 strains became highly pathogenic they even revert to nonpathogenic in ducks. Ducks experimentally infected with viruses isolated between 2003 and 2004 shed virus for an extended time (up to 17 days). These results suggest that the duck has become the "Trojan horse" of Asian H5N1 viruses.
The ducks that are unaffected by infection with these viruses continue to circulate these viruses, presenting a pandemic threat. ${ }^{20}$

This finding suggests a trend toward decreased pathogenicity of $\mathrm{H} 5 \mathrm{~N} 1$ in ducks, although the small number of samples tested (because of time, and reagents constraints) precludes a firm conclusion. As reported by Chen et al. ${ }^{21} \mathrm{H} 5 \mathrm{~N} 1$ viruses isolated from healthy ducks remain pathogenic to chickens and mammals. Therefore, the duck may be resuming its role as a reservoir of $\mathrm{H} 5 \mathrm{~N} 1$ viruses, transmitting them to other bird species and potentially to mammals. As the seropositive results were obtained during identified $\mathrm{H} 5 \mathrm{~N} 1$ outbreaks, they may not be representative of the endemic $\mathrm{H} 5 \mathrm{~N} 1$ virus population in the result. There may be many more ducks infected with low of high pathogenic viruses than are currently depicted from the serological tests. Passive surveillance and outbreak reports will underestimate the prevalence of $\mathrm{H} 5 \mathrm{~N} 1$ in duck population and the role played by ducks in HPAI outbreaks.

According to Karki et al. ${ }^{9} 27.2 \%$ of domestic ducks sampled in Kathmandu were positive for AIV antibodies, with duck age found to be a significant risk factor for AIV seropositivity.

In similar study by Karamcharya et $\mathrm{al}^{3}{ }^{3}$ they found only one Influenza A H9N2 positive out of 1811 environmental fecal samples collected from seven wetland migratory bird roosting areas. It was found in one sample from a ruddy shelduck in Koshi Tappu Wildlife Reserve located in southern Nepal. In contrast, Avian H7N9 and other highly pathogenic avian influenza viruses were not detected.

Region-wide influenza virus surveillance among healthy ducks across the country including domestic ducks, waterfowl, migratory birds and wild birds is merited to determine whether highly pathogenic $\mathrm{H} 5 \mathrm{~N} 1$ is endemic in domestic birds. Such an initiative would elucidate the true impact and role of domestic ducks in the continual spread of $\mathrm{H} 5 \mathrm{~N} 1$ viruses. The mechanism of non-pathogenicity of $\mathrm{H} 5 \mathrm{~N} 1$ among ducks increases the potential for spread of these viruses; it is biologically, helping to explain the origin of new $\mathrm{H} 5 \mathrm{~N} 1$ viruses in inter-species population. This finding also has public health implications. There is a real possibility that if these $\mathrm{H} 5 \mathrm{~N} 1$ viruses continue to circulate, further human infection will occur, increasing the potential for human-to-human transmission.

As found by Gilbert \& Singenbergh ${ }^{2}$ there is a high rate of $\mathrm{H} 5 \mathrm{~N} 1$ influenza virus infection in the domestic ducks in Vietnam region, and the duck density has been strongly correlated with H5N1 outbreaks in Thailand. Therefore, the role of the duck in the outbreaks should be investigated further. For that, the molecular characterization of AI H5N1 virus from the ducks and infected poultry (i.e. dead poultry from HPAI in Nepal) should be analyzed in coming years.

\section{Conclusion}

From the present study, it can be concluded that there is presence of sero-prevalent cases among backyard ducks for avian influenza type A subtype H5 and H9 antibody in Nepal though they have not been shown any symptomatic characteristics for the HPAI or LPAI avian influenza infection.

For the detection of antibodies in the different species of ducks to avian influenza A subtype $\mathrm{H} 5, \mathrm{H} 9$ and $\mathrm{H} 7$; $\mathrm{HI}$ test was carried out. It was further confirmed by using FLUDETETTM BE (Blocking ELISA). Due to the easy operating procedures without sophisticated equipments, HA/HI tests are suitable and feasible enough for the surveillance purpose in developing countries like Nepal. In addition, the Blocking ELISA is also found to be more sensitive and can be used routinely provided the serum samples are in abundant. These tests are 
being less technical than molecular diagnosis and can be completed within several hours.

Though HA/HI test can be applied to detect avian influenza A subtype, it cannot be used to detect the neuraminidase type as well as the virus's molecular characterization for identifying the emerging source.

\section{Impacts}

a. The study shows evidence of sero-prevalent cases among backyard ducks for avian influenza type A subtype H5 and H9 antibody in Nepal.

b. All the positive $\mathrm{H} 5$ samples were from the month of December.

c. The role of domestic ducks represents a major risk for emergence of AVI H5 in Nepal.

\section{Acknowledgments}

None.

\section{Conflicts of interest}

None.

\section{References}

1. Li KS, Guan Y, Wang J et al. Genesis of a highly pathogenic and potentially pandemic $\mathrm{H} 5 \mathrm{~N} 1$ influenza virus in eastern Asia. Nature. 2004;430(6996):209-213.

2. Gilbert M, Xiao X, Pfeiffer DU, Epprecht M et al. High pathogenic Avian Influenza in Thailand: An analysis of the distribution of outbreaks in the second wave, identifications of risk factors and prospects for real-time monitoring (FAO (UN) Rome and Ministry Agriculture. Cooperatives, Bangkok, Thailand. 2006

3. Karmacharya D, Manandhar S, Sharma A et al. Surveillance of Influenza A Virus and Its Subtypes in Migratory Wild Birds of Nepal. Plos One. 2015;10(7):e0133035

4. Hinshaw VS, Bean WJ, Webster RG, Sriram G Genetic reassortment of influenza A viruses in the intestinal tract of ducks. Virology. 1980;102(2):412-419.

5. Pant GR, Selleck PW Surveillance for avian influenza in Nepal 2004-2005. Avian Disease. 2006;51(Suppl 1): 352-354.

6. Globig A, Staubach C, Beer M et al. Epidemiological and ornithological aspects of outbreaks of highly pathogenic avian influenza virus H5N1 of Asian lineage in wild birds in Germany, 2006 and 2007. Transbound Emerg Dis. 2009;56(3):57-72.

7. CDC Spread of Avian Influenza. Viruses among Birds, USA. 2008
8. Kim JK, Negovetich NJ, Forrest HL, Webster RG Ducks: The Trojan Horses of H5N1 influenza. Influenza Other Respir Viruses. 2009;3(4):121-128.

9. Karki S, Lupiani B, Budke CM Cross-Sectional Serosurvey of Avian Influenza Antibodies Presence in Domestic Ducks of Kathmandu, Nepal. Zoonoses Public Health. 2014;61(6):442-448.

10. Shrestha L Surveillance of Avian Influenza in Nepal. An M Sc. Thesis Submitted in Partial Fulfillment of the Requirements for the Award of the Degree of Master of Science in Microbiology (Environmental and Public Health), Department of Microbiology, National College (Affiliated to Tribhuvan University), Nepal CDC. 2008

11. Al-Natour MQ, Abo-Shehada MN Sero-prevalence of avian influenza among broiler-breeder flocks in Jordan. Prev Vet Med. 2005;70(1-2):45-50.

12. Naeem K, Naurin M, Rashid S, Bano S Seroprevalence of avian influenza virus and its relationship with increased mortality and decreased egg production. Avian Pathol. 2003; 32(3):285-289.

13. Numan M, Siddique M, Ashraf M, Khan HA, Yousaf MS Quantification of antibodies against avian influenza virus subtype H7N3 in layer flocks in central Punjab. International Journal of Agriculture and Biology. $2005 ; 4: 564-566$

14. Adair BM, Todd D, McKillop ER et al. Detection of influenza A type specific antibodies in chicken and turkey sera by enzyme linked immunosorbent assay. Avian Pathol. 1989;18(3):455-463.

15. Arenas A, Carranza J, Perea A et al. Type A influenza virus in birds in Southern Spain: serological survey by enzyme -linked Immunosorbent assay and hemagglutinin test. Avian Pathol. 1990;19(3): 539-546.

16. FAO FAO's response to avian flu. Food and Agriculture Organization. 2005

17. Sala G, Cordioli P, Moreno-Martin A et al. ELISA test for the detection o f influenza H7 antibodies in Avian sera. Avian Dis. 2003;47(3 Suppl):1057-1059.

18. Hinshaw VS, Webster RG, Easterday BC Replication of avian influenza A viruses in mammals. Infect Immun.1981;34(2):354-361.

19. Rowe T, Abernathy RA, Hu-Primmer J et al. Detection of antibody to avian influenza A (H5N1) virus in human serum by using a combination of serologic assays. J Clin Microbiol. 1999;37(4):937-943.

20. Hulse-Post DJ, Sturm-Ramirez KM, Humberd J et al. Role of domestic ducks in the propagation and biological evolution of highly pathogenic H5N1 influenza viruses in Asia. Proc Natl Acad Sci U S A. 2005;102(30):10682-10687.

21. Chen H, Deng G, Li Z, Tian G et al. The evolution of H5N1 influenza viruses in ducks in southern China. Proc Natl Acad Sci U SA. 2004;101(28):10452-10457. 